\author{
Ewa Szymanek \\ Institute of Thermal Machinery, Faculty of Mechanical Engineering and Computer Science, \\ Czestochowa University of Technology, Armii Krajowej 21, 42-201 Czestochowa, ewaszymanek@vp.pl
}

\title{
USE OF FRACTIONAL CALCULUS IN MODELING OF HEAT TRANSFER PROCESS THROUGH EXTERNAL BUILDING PARTITIONS
}

\begin{abstract}
This paper is devoted to experimental and numerical studies of heat distribution in an external building bulkhead. It analyzes the variation of temperature across the width of the bulkheads including the impact of changing external conditions. Mathematical model used in the research is formulated based on a fractional differential equation, which was proven to be a useful tool for describing this type of process in previous paper. Numerical results are compared with experiment data for different bulkhead configurations.
\end{abstract}

\section{Key words}

Fractional equations, building bulkhead, heat flow

\section{Introduction}

Reduction of the negative human impact on the climate is one of the challenges for European Union Member States, which is reflected in both its legislation and strategic priorities adopted in the next financial perspectives $[1,2,3,4]$. Currently, EU actions are aimed, among other things, at reducing the greenhouse gas emissions by $80 \%$ by 2050 year compared to the 1990 level with transition stages up to 2030 (40\% reduction) and until 2040 (40\% reduction). Undoubtedly, realization of such assumptions requires an active participation of all Member States. That is why in recent years a huge progress has been made in Poland in the field of energy efficiency. In the national legislation on energy, environmental protection and construction law, significant changes have been introduced to support energy efficiency $[5,6,7]$. Certainly, the leading roles in a low-emission economy will be played by sustainable construction. Due to the low standard of a large part of Polish buildings, the energy consumption is inefficient. In many cases the consumed energy is wasted as the heat "escapes" through poorly constructed and insulated walls and roofs. The most important challenge for achieving such results in 2050 will be thermo-modernization of existing buildings. It should be emphasized that currently as much as 70 percent of flats and houses in Poland are not insulated, and their thermomodernization would allow at low cost to reduce the heat losses, which could cause significant a drop in energy demand. At present, at the investment stage, which requires a building permit, energy-saving documents are necessary. One of the actions that are taken to improve the energy parameters in existing buildings is the insulation of external walls, where the heat losses are in the range $24 \%-35 \%$. The most common is the insulation in the form of adding additional insulating material to the existing wall from outside. Partitions (walls) used in the construction industry consist of many layers of different materials firmly adjacent to each other. Styrofoam or mineral wool layer are the most popular, however, fillings in the form of rigid foam or various mixtures are also used [8]. Knowledge of physical processes and chemical phenomena occurring in building materials [9] facilitates their proper selection and allows designing buildings with regard to energy saving [10]. Heat transfer occurring in the interior of solid materials consists in the transfer of energy between adjacent particles. The intensity of this process depends on the structure and properties of the material. That is why the construction of external partitions is very important in construction industry. The basis of the heat exchange phenomenon is the temperature difference. Therefore, one should look for solutions that allow to correctly defining the temperature distribution in its interior. More accurate understanding of the heat transfer phenomenon between particular bulkhead layers (insulating walls) will allow better control of temperature changes. A big problem in the detailed description of the heat flow process is the multitude of dependencies and factors needed to describe the structure of insulating walls. Definition of general dependence allowing determining the thermal conductivity is complicated due to the thermal properties of individual components.

From the literature it can be stated that in the classic approach the heat flow is described by the Kirchhoff equation. The basic disadvantage of this model is the necessity of knowing all material parameters of the insulating layers and the numerous empirical correlations needed to describe their thermal properties. For this reason, in this work it was decided to move away from the classic approach and replace it with a new model 
based on fractional calculus. Models using the fractional derivatives are considered to be an excellent tool for describing the memory and hereditary properties of various materials and processes. Fractional differential equations, both ordinary and partial, are used in the modelling of various phenomena in the fields of physics, mechanics, control theory, biochemistry, bioengineering and economics [11-17]. Their application is also found in mechanics, in the field of signal processing [18] and in modelling of phenomena occurring in construction industry [19]. As a result, the fractional differential equations gain more and more applications and importance. In [20] the classical thermal conductivity equation was replaced with an ordinary differential equation containing the composition of the left and right-sided fractional derivative. The equations of this type are obtained by modification the least action principle and the use of fractional method of integration by parts $[21,22,23]$. One of the basic problems which appears while modelling the heat flow in a complex system is the multiplicity of interrelations, factors and coefficients necessary to describe the structure of the examined system. This paper proposes a description which does not investigate the structure but assumes some degree of its heterogeneity. When used with a simple differential equation including left- and right-sided fractional derivatives we arrive at a model which has such a quality that it does not investigate the structure and does not include such a number of factors. The considered problems faced in the process of heat flow during the paper will be analysed from the practical and theoretical points of view. In this paper a fractional differential equation containing the left and right-sided Caputo derivative in the restricted area was applied. One of the basic problems that arise in the fractional equations is a lack or very complex form of analytical solutions. The fractional equation are discretized because the results obtained so far, including those based on the fixed-point theorem [24], do not give the possibility to apply them in practice. The solution in discretized form is presented as a series of left and right sides of fractional integrals. In the paper, the simulations of heat flow through one, two and three-layer barriers were performed and their inner temperature distributions were determined. The results obtained using the commercial Leca program are also presented. A description of the temperature distribution based on fractional calculus has been proposed and the obtained results were compared with the experimental data.

\section{Experiment}

Simulations of heat flow and temperature distributions in building partitions allow designing them in a way reducing the cost of building to minimum. Because external walls have a big influence on the energetic characteristics of the buildings the knowledge of temperature distributions inside them is so important. It allows correct evaluation of their insulation. The article presents the results of research on the heat flow through the external layers with three types of partitions: one-layer, two-layer and three-layer.

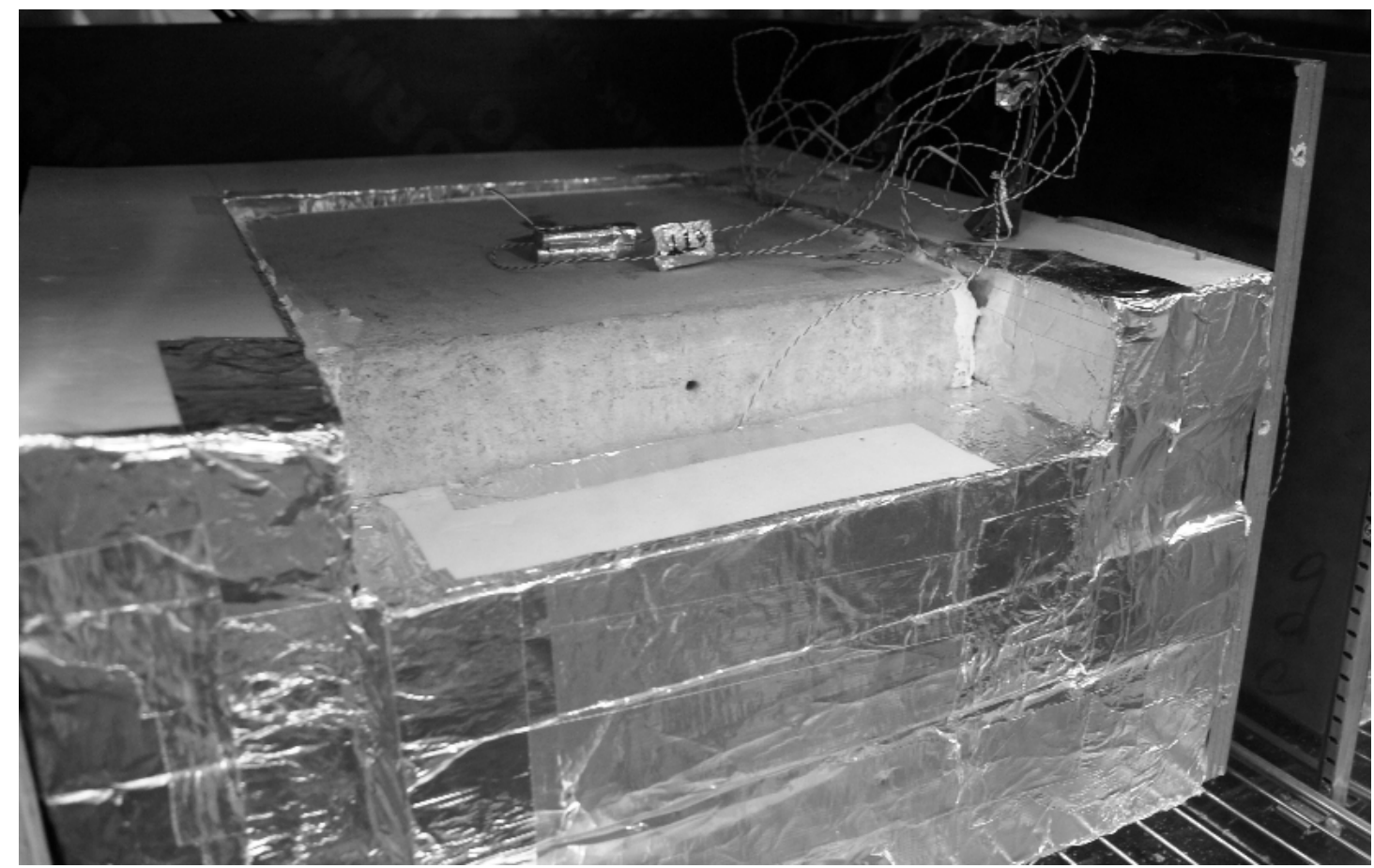

Fig.1. A partition prepared for testing

Source: Author's 
The first of them was built of cellular concrete $(48 \mathrm{~cm})$. The two-layer partition $(48 \mathrm{~cm})$ consisted with cellular concrete layer $(32 \mathrm{~cm})$ and was additionally supplemented with a layer of styrofoam EPS $032(16 \mathrm{~cm})$. The three-layer partition $(48 \mathrm{~cm})$ consisted of a cellular concrete layer $(32 \mathrm{~cm})$, styrofoam EPS $032(8 \mathrm{~cm})$ and an elevation brick $(8 \mathrm{~cm})$. Each wall was covered on both sides with cement and lime plaster. The thermal parameters of the materials used were as follows: concrete (density $2100 \mathrm{~kg} / \mathrm{m}^{3}$, thermal conductivity coefficient 1,1 W/(m.K), specific heat $840 \mathrm{~J} /(\mathrm{kg} \cdot \mathrm{K})$ ), styrofoam EPS 032 (density $40 \mathrm{~kg} / \mathrm{m}^{3}$, thermal conductivity coefficient 0,032 W/(m.K), specific heat $1460 \mathrm{~J} /(\mathrm{kg} \cdot \mathrm{K})$ ), elevation brick (density $1900 \mathrm{~kg} / \mathrm{m}^{3}$, thermal conductivity coefficient $1,05 \mathrm{~W} /(\mathrm{m} \cdot \mathrm{K})$, specific heat $880 \mathrm{~J} /(\mathrm{kg} \cdot \mathrm{K}))$. Measurements of thermal conductivity were carried out using a plate apparatus with a a heat flux density sensor HFM P.A. Hilton B480. The specific heat was determined by the calorimetric method, while the density measurement was based on Archimedes' law. An example of the tested wall composed of two layers (cellular concrete and styrofoam) is presented in Figure 1.

Figure 2 presents a symbolic construction of the tested wall and temperature distribution in one, two and three-layer partitions determined using the commercial calculation program Leca. It can be seen that the temperature across particular layers changes linearly. As will be shown later such an approximation is inconsistent with the experiment and simulations performed by the fractional calculus method.
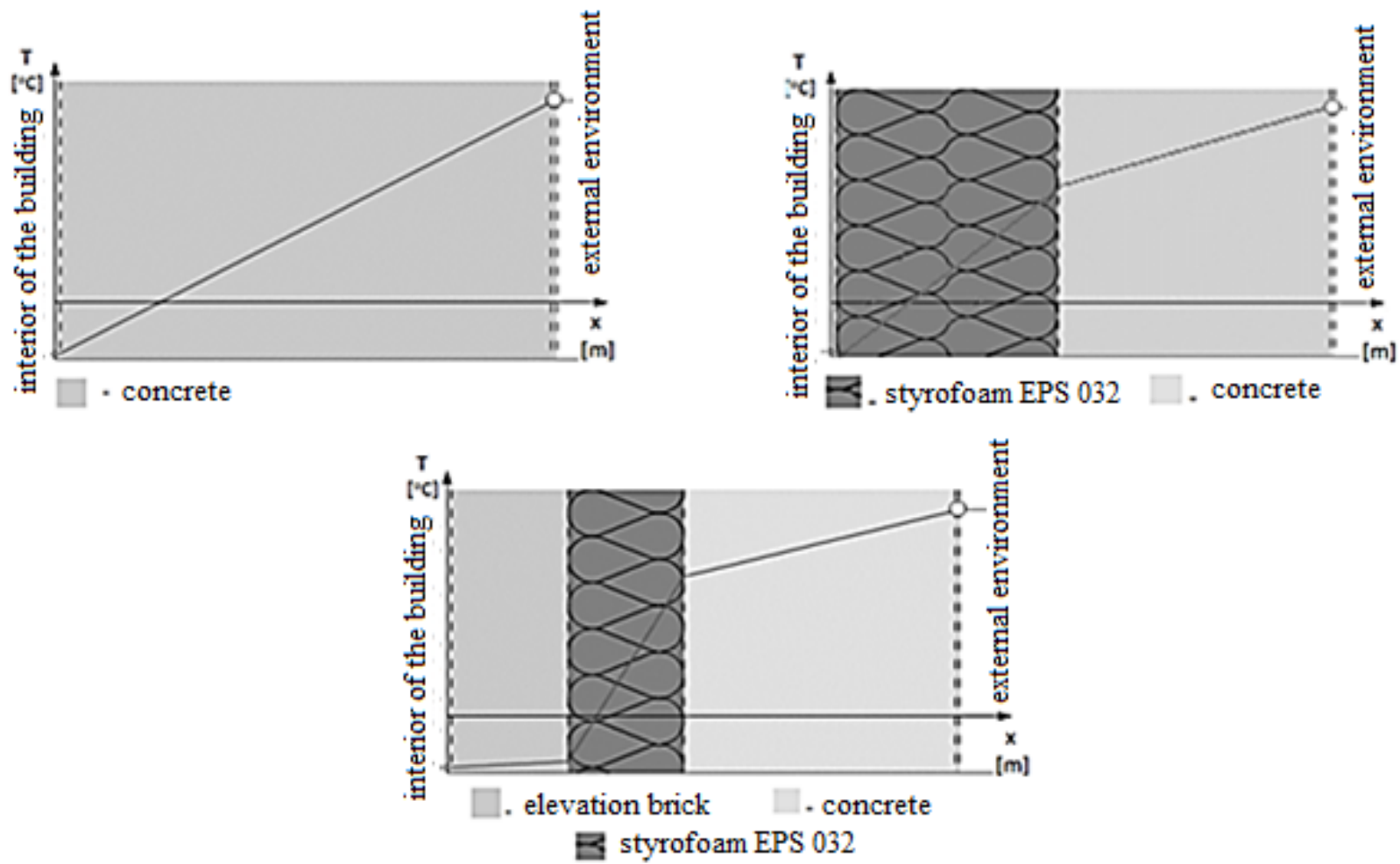

Fig.2. Construction and distribution of temperatures in one, two and three-layer partitions determined by Leca's commercial calculation program.

Source: Author's

Measurements of the temperature were performed by thermocouples placed in the holes drilled inside the layers. Empty spaces between the test center and the thermocouple were filled with drilling dust or pieces of styrofoam, so that the thermocouple adhered closely to the material tested. The tested partitions were $30 \times 30 \times 48 \mathrm{~cm}$. Thermocouples in each partition were placed on 7 levels (level every $8 \mathrm{~cm}$ ). Five thermocouples were installed in each of the following configurations $(\mathrm{cm}, \mathrm{cm}): \mathrm{T} 1:(X, Y)=(7.5,7.5), \mathrm{T} 2:(X, Y)=(7,5,22.5)$, T3: $(X, Y)=(15.15), T 4:(X, Y)=(22.5,7.5), T 5:(X, Y)=(22.5,22.5)$. This arrangement was intended to minimize measurement errors. As the data from the thermocouples on the individual levels were similar, they were averaged and added as one measuring point on the graph. The walls constructed in this way were placed in a climatic chamber (Fig. 3), which enabled setting of external temperatures and their precise control during the whole experiment. External temperature values were changed in a similar way to daily temperature fluctuations in Poland. 


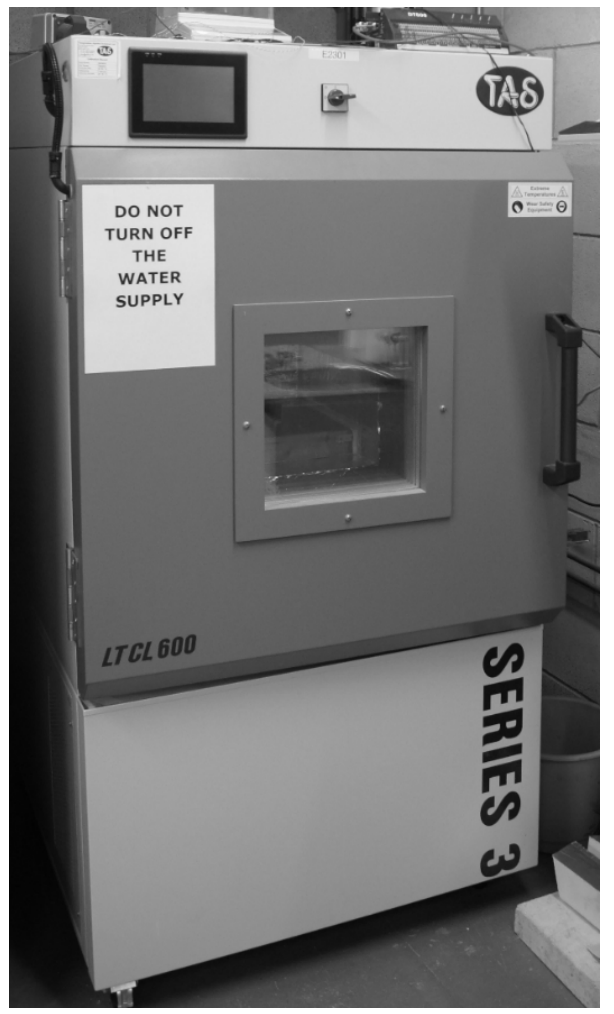

Fig.3. Climatic chamber Source: Author's

\section{Model}

The complexity of the heat transfer process generates the need to create new models for its description. Numerical methods, such as the method based on fractional calculus, are increasingly being used for such purposes. As already mentioned, in the comparison to classical methods it requires much smaller number of coefficients. In this work we apply an ordinary differential equation containing the composition of left and right-sided derivatives of a non-integer order. To describe the considered phenomenon, a non-integer equation is proposed with the left and right-sided Caputo derivative in the form:

$$
{ }^{C} D_{b-}^{\alpha{ }^{C}} D_{a+}^{\alpha} T(x)+\lambda T(x)=0, x \in[a, b] .
$$

where $T$ - temperature, $\lambda$ - scale parameter, $\alpha$ - order of derivative. The fractional derivatives have the following form [25]:

$$
\begin{aligned}
& { }^{C} D_{a+}^{\alpha} T(x)=\frac{1}{\Gamma(1-\alpha)} \int_{a}^{x} \frac{T^{\prime}(\tau)}{(x-\tau)^{\alpha}} d \tau \\
& { }^{C} D_{b-}^{\alpha} T(x)=\frac{-1}{\Gamma(1-\alpha)} \int_{x}^{b} \frac{T^{\prime}(\tau)}{(\tau-x)^{\alpha}} d \tau
\end{aligned}
$$

The formulas (2) and (3) are respectively the left-sided and the right-sided Caputo derivative. It is assumed that temperature varies only in the " $x "$ direction perpendicular to the partition. 
Equation (1) has been supplemented with the boundary conditions:

$$
\begin{aligned}
& T(0)=T a \\
& T(L)=T b
\end{aligned}
$$

where the length of the layer is assumed $L=1$.

\section{Numerical solution}

Here, mathematical analysis is used increasingly often for designing granular material assemblies, such as, for example, fractional differential equation, which requires a significantly-smaller number of coefficients. The form of the analytical solution of equation (1) is complicated [26] and it is not possible to apply it for the analysed phenomenon. Therefore, equation (1) is discretized by means of a series of expansions with coefficients $v$. Along with the boundary conditions (4) it can be written in the following form [20,27]:

$$
\begin{gathered}
\mathrm{T}_{\mathrm{a}}=\mathrm{Ta} \\
\sum_{\mathrm{k}=\mathrm{i}}^{\mathrm{n}}\left[v(\mathrm{n}-\mathrm{i}, \mathrm{n}-\mathrm{k}) \cdot \sum_{\mathrm{j}=0}^{\mathrm{k}} v(\mathrm{k}, \mathrm{j}) \mathrm{T}_{\mathrm{j}}\right]+\lambda \mathrm{T}_{\mathrm{i}}=0, \quad \text { for } \mathrm{i}=1, \ldots, \mathrm{n}-1 \\
\mathrm{~T}_{\mathrm{b}}=\mathrm{Tb}
\end{gathered}
$$

where $\mathrm{n}$ is number of nodes, $T_{i}$ is the value of the function $T$ at point $x_{i}$ and coefficient $v$ is defined as

$$
v(i, j)=\frac{(\Delta x)^{\alpha}}{\Gamma(2-\alpha)}\left\{\begin{array}{cl}
-i^{1-\alpha}+(i-1)^{1-\alpha} & \text { for } \\
(i-j+1)^{1-\alpha}-2(i-j)^{1-\alpha}+(i-j-1)^{1-\alpha} & \text { for } j=0 \\
1 & \text { for } \quad j, \ldots, i-1
\end{array}\right.
$$

where $\Delta x=L /(N-1)$ stands for a distance between the computational nodes, which number changes in the range $N=20 \div 140$. The symbol $\Gamma$ in Eq.(6) is the Gamma function.

The convergence rate (EOC) of series (5) for parameters $T a=1, T b=0$ and $\lambda=0.02$ is determined according to the equation:

$$
E O C=\frac{1}{9} \sum_{i=1}^{9} E O C_{i, \alpha}^{(\Delta x)}
$$

where

$$
\operatorname{EOC}_{i, \alpha}^{(\Delta x)}=\log _{2}\left(\frac{t_{i, \alpha}^{(\Delta x)}-t_{i, \alpha}^{(2 \Delta x)}}{t_{i, \alpha}^{(\Delta x / 2)}-t_{i, \alpha}^{(\Delta x)}}\right)
$$

is the order of the method determined on the basis of one of 9 selected points in the computation area. Analysis of convergence rate was determined for four computation grids with $\Delta x=1 / 20,1 / 40,1 / 80,1 / 120$. Note that $t_{i, \alpha}^{(\Delta x)}$ are numerical value in the points $x_{i / 10 \Delta x}$ for $i=1,2, \ldots, 9$. Table 1 shows the EOC values for $\alpha \in\{0.1,0.3,0.5,0.7,0.9\}$ and $\lambda=0.02$. 
Tab. 1. Estimation of the discretization order of (5) for four computational grids

\begin{tabular}{|c|c|c|c|c|c|}
\hline & \multicolumn{5}{|c|}{ EOC } \\
\hline$\Delta x$ & $\alpha=0.1$ & $\alpha=0.3$ & $\alpha=0.5$ & $\alpha=0.7$ & $\alpha=0.9$ \\
\hline $1 / 20$ & 1.21 & 1.11 & 0.96 & 0.80 & 0.65 \\
\hline $1 / 40$ & 1.10 & 1.08 & 1.00 & 0.87 & 0.74 \\
\hline $1 / 80$ & 1.05 & 1.05 & 1.00 & 0.91 & 0.79 \\
\hline $1 / 120$ & 1.03 & 1.03 & 1.00 & 0.94 & 0.83 \\
\hline
\end{tabular}

\section{Source: Author's}

Analysing the values in Table 1, it can be observed that the convergence rate of (5) slightly depends on the $\alpha$ parameter and its value is close to 1 . Figure 4 presents the solutions of equation (1) for different values of the parameter $\alpha$. It shows that the temperature profiles are strongly dependent on it. The deviation of $\alpha$ from integer value (equal to 1 in classical approach) causes that the obtained solutions behave as if they were obtained using the classical method with variable heat conductivity of the layer.

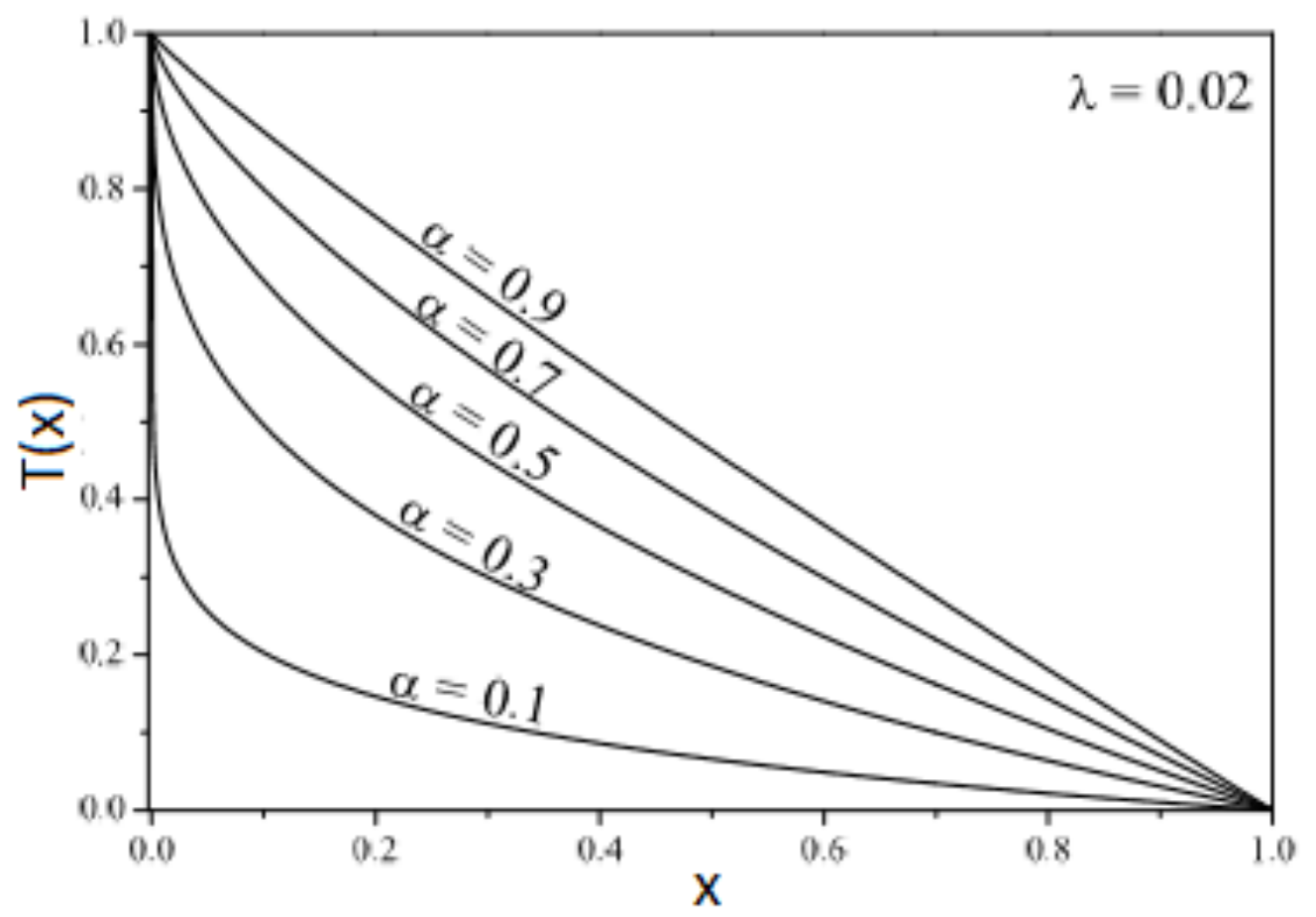

Fig. 4. Numerical solutions of the equation (1) for $\lambda=0.02$ I $\alpha \in\{0.1 ; 0.3 ; 0.5 ; 0.7 ; 0.9\}$ Source: Author's

\section{Results}

Figures 5-7 present the experimental and numerical temperature profiles inside the partitions. The temperature distributions were determined for the outside temperature $\mathrm{T}(\mathrm{L})$ changing from $-20^{\circ} \mathrm{C}$ to $18^{\circ} \mathrm{C}$ at the outer layer. The steady states were selected for further analysis. In this case we considered the layers with $\mathrm{L}=48 \mathrm{~cm}$. The temperature on the inner side $\mathrm{T}(0)$ was computed assuming the Neumann boundary conditions. During the experiment, the thermocouples were placed in the same distance from each other and from the outer and inner layers. The graphs show experimental data for selected time moments. The results presented 14,200 second from the beginning of measurements when the outside temperature was $9^{\circ} \mathrm{C}$. For comparison the results obtained using the classical approach are also presented in the figures. They are denoted as "mathematical integer order". It can be seen that the results obtained the fractional order are much more accurate. 


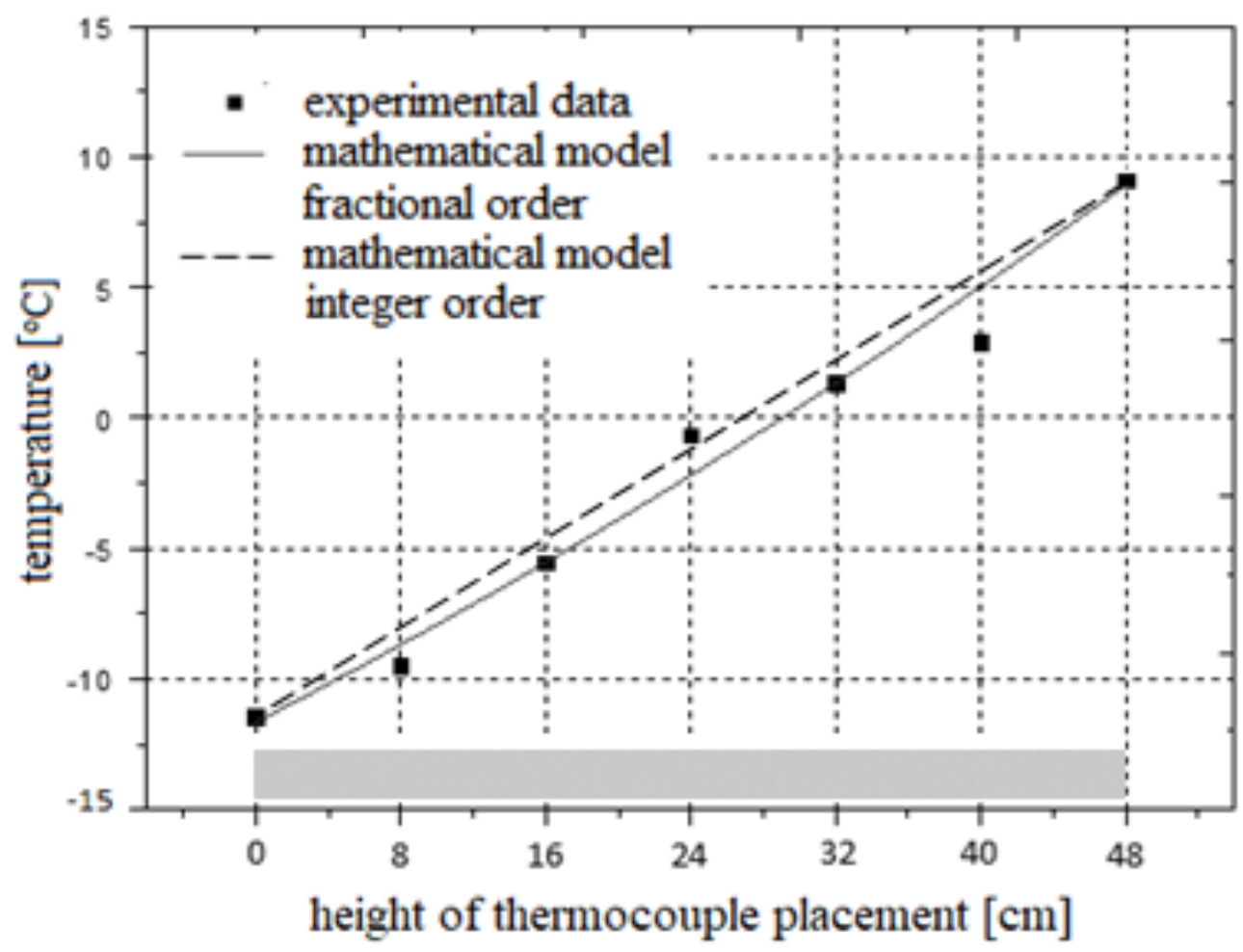

Fig. 5. Comparison of the numerical solution with experimental data for a single-layer partition for an external temperature of $9^{\circ} \mathrm{C}, \alpha=0,85$ Source: Author's

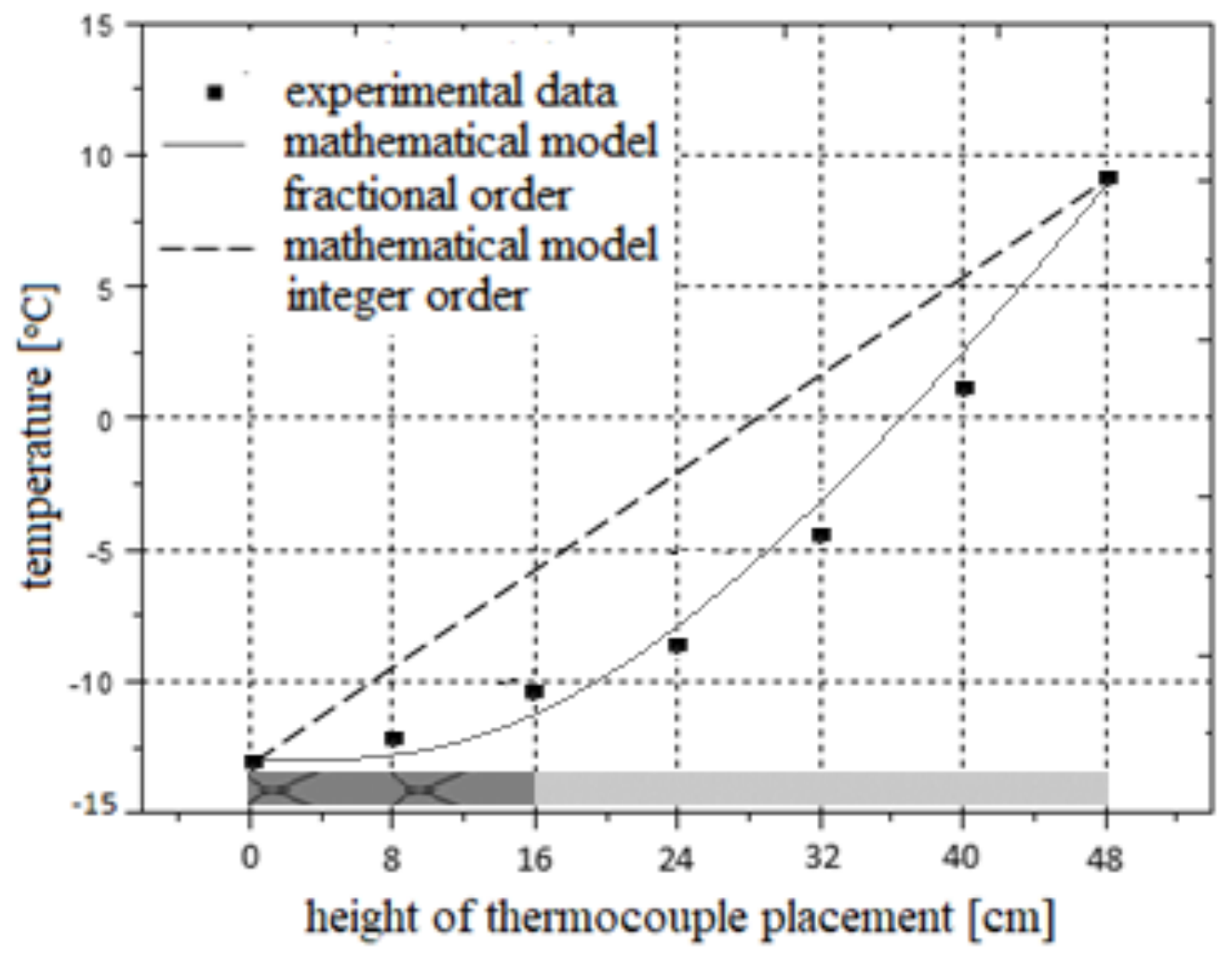

Fig.6. Comparison of the numerical solution with experimental data for a two-layer partition for an external temperature of $9^{\circ} \mathrm{C}, \alpha=0,25$

Source: Author's 


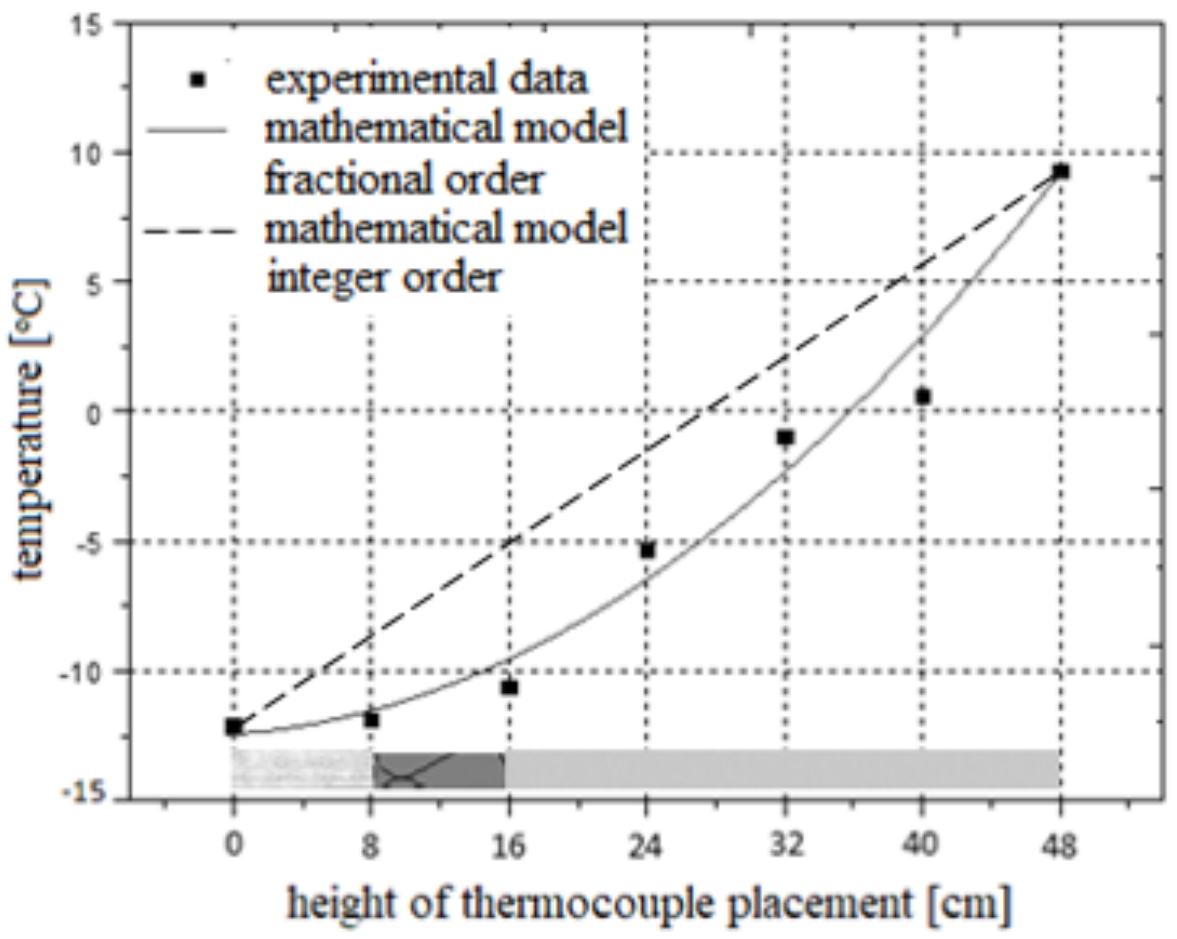

Fig.7 Comparison of a numerical solution with experimental data for a three-layer partition for an external temperature of $9^{\circ} \mathrm{C}, \alpha=0,3$

Source: Author's

As can be seen in Fig.5 for the monolayer partition consisting of cellular concrete the measured data only slightly differ from the simulation results. It is visible that at all measuring points the deviations were at a similar level. Accidental larger discrepancies could be due to a measurement error estimated at $2^{\circ} \mathrm{C}$. Differences in temperature values for two-layer partition are also small, as can be seen in Fig.6. Depending on the measurement point, the results are over and underestimated in relation to the experimental data. These fluctuations did not occur regularly and therefore their origin could not be identified. The largest deviations from the curve obtained on the basis of simulations can be seen for three-layer partition (see Fig. 7). The differences occur here in the whole width of the partition and are the most pronounced among the tested partitions. Most likely, in this case the discrepancies between the simulation and measurements results from a complex structure of partitions. However, the trend of the temperature variations is well captured. In general, when comparing experimental data with the results of a fractional model, it can be noticed that the differences between experimental and numerical data are small. The method proposed in this paper allows modelling of real external temperature changes and allows for analysis of temperature distribution inside the partitions.

\section{Summary}

The article presented the results of research on heat transfer phenomenon in external building walls composed of one, two and three-layered partitions. The experimental tests and simulations were conducted under variable temperature conditions reflecting daily temperature fluctuations. Both the cellular concrete layer and the insulator were considered, which in the present case was a styrofoam and a material in the form of a elevation brick. The mathematical model presented in the paper was based on fractional differential calculus and it turned out to be an efficient and accurate tool, which characterized stable convergence rate. The proposed model allows to describe the theoretical problem of thermal conductivity and may be regarded as an alternative to others classical approaches known for problems with the multitude of different types of correlations and coefficients. Relatively small differences between the numerical and experimental results indicate high accuracy of the proposed model. It is believed that it can be used for optimization purposes during the construction of partitions, achieving measurable economic effects. 


\section{Acknowledgements}

This work was supported by National Science Centre, Poland (Grant no. 2017/27/N/ST8/02318). The author is grateful to A. Tyliszczak for his fruitful comments on the initial version of this manuscript.

\section{References}

[1] COM, 885 final, Commission communication Energy Action Plan by 2050

[2] Report from the Commission to the European Parliament and the Council, Evaluation of Member States' progress towards national targets for energy efficiency 2020 and progress in implementing Directive 2012/27 / EU on energy efficiency as required by Art. 24 sec. 3 of Directive 2012/27 / EU on energy efficiency, Brussels, 13.1.2017, COM (2015) 574.

[3] Directive of the European Parliament and of the Council 2012/27 / EU of 25 October 2012 on energy efficiency

[4] The Energy Performance of Buildings Directive 2002/91/EC

[5] Energy policy of Poland until 2030, pp.7-8, http: //www.mg.gov.pl/ Bezpieczenstwo + gospodarcze/ Energetyka /Polityka + energetyczna

[6] Monitor Polski, Dziennik Urzędowy Rzeczpospolitej Polskiej, Warszawa, dnia 16 lipca 2015 r. Poz. 614 Uchwała nr 91 Rady Ministrów z dnia 22 czerwca 2015 r. w sprawie przyjęcia „Krajowego planu mającego na celu zwiększenie liczby budynków o niskim zużyciu energii"

[7] http: //www.mg.gov.pl/ bezpieczeństwo + gospodarcze/Energetyka/Efektywnosc + energetyczna

[8] J. Mikoś, Budownictwo ekologiczne, Wydawnictwo Politechniki Śląskiej, Gliwice, 2000

[9] E. Kotela, J. Leszczyński, T. Błaszczyk, M. Hall, Wykorzystanie rachunku różniczkowego niecałkowitego rzędu do opisu jednowymiarowego profilu temperatury w stanie ustalonym, II Kongres Mechaniki Polskiej, 2931.08.2011, Poznań

[10] W. Dubas, Podstawy budownictwa energooszczędnego, Budownictwo energooszczędne, Przegląd budowlany 5/2006

[11] J. Sabatier, O. Agrawal, M. Tenreiro Machado, Advances in Fractional Calculus. Theoretical Developments and Applications in Physics and Engineering, Springer-Verlag, Berlin 2007

[12] R.L. Magin, Fractional Calculus in Bioengineering, Begell House Inc., Redding, 2006

[13] E. Scalas, R. Gorenflo, F. Mainardi, Fractional calculus and continuous time finance, Physica A, 284, (2000), 376-384.

[14] T.K. Nowak, K. Duzinkiewicz, Analiza modelu ułamkowego rzędu procesów szybkich reaktora jądrowego, 1, (2014), 44-47.

[15] M. Długosz, P. Piątek, J. Baranowski, P. Skruch, Algorytmy sterowania i zarzadzania budynkami mieszkalnymi, AGH Akademia Górniczo-Hutnicza,(skrypt), Wydział EAliE, Katedra Automatyki.

[16] A. Loverro, Fractional Calculus: History, Definitions and Applications for the Engineer, Department of Aerospace and Mechanical Engineering University of Notre Dame Notre Dame, IN 46556, (2004).

[17] M. Dalir, Applications of Fractional Calculus, Applied Mathematical Sciences, 4 (21), (2010, 1021 1032 
[18] B. Kuldeep, A. Kumar, G.K. Singh, Design of quadrature mirror filter bank using Lagrange multiplier method based on fractional derivative constraints, Engineering Science and Technology, (2015).

[19] E. Szymanek, The application of fractional order differential calculus for the description of temperature profiles in a granular layer, Advances in the Theory and Applications of Non-integer Order Systems, (257), (2013), 243-248.

[20] T. Błaszczyk, E. Kotela, M.R. Hall, J.S. Leszczyński, Analysis and applications of composed forms of caputo fractional derivatives, ActaMechanica et Automatica, (2011), 1-4.

[21] O.P. Agrawal, Formulation of Euler-Lagrange equations for fractional variational problems, J. Math. Anal. Appl., 272, (2002), 368-379.

[22] M. Klimek, Lagrangean and Hamiltonian fractional sequential mechanics, Czech. J. Phys., 52, (2002), 1247-1253.

[23] F. Riewe, Nonconservative Lagrangian and Hamiltonian mechanics, Phys. Rev. E, 53, (1996), 18901899.

[24] M. Klimek, Solutions of Euler-Lagrange equations in fractional mechanics, AIP FgrunConference Proceedings 956. XXVI Workshop on Geometrical Methods in Physics. Bialowieza, (2007), 73-78.

[25] A.A. Kilbas, H.M. Srivastava, J.J. Trujillo, Theory and Applications of Fractional Differential Equations, Elsevier, Amsterdam, (2006).

[26] M. Klimek, G -Meijer functions series as solutions for certain fractional variational problem on a finite time interval. Journal Europeen des Systemes Automatises (JESA) 42, 653-664 (2008)

[27] T. Blaszczyk, M. Ciesielski, M. Klimek, J. Leszczynski, Numerical solution of fractional oscillator equation. Appl. Math. Comput. 218, (2011),2480-2488. 